\title{
Addiction Research in Switzerland and Elsewhere in Europe
}

The reporting on issues of addiction by mass media these last months might lead to the impression that the Swiss study on the medical prescription of opiates is about the only interesting and important event in the field of addiction research, and that Switzerland is the only country, perhaps apart from the Netherlands, where anything new in the way of addiction research is going on. Opiate and especially heroin addiction always exerted an almost magical attraction on the political debate and the public interest. For many people, heroin addiction is synonymous with addiction in general, and is associated with the almost inescapable danger of social decline. Drug deaths, impoverishment, crime and prisons full of opiate addicts, those are the highlights offered by television and the daily press to the eager eyes of a fascinated audience. At the same time, the wave of ecstasy among adolescents, not to mention the mass drugs nicotine, alcohol and cannabis, are almost completely thrust into the background. This focus on heroin has an almost mystical component that has been part of the heroin discussion for 200 years, after a period of 3 millenniums when opiates had their place among the medicines of all those concerned with healing. Thus, the way opiates are viewed by society mirrors the way society deals with addiction, whereas many more people suffer or die from the results of nicotine than from those of heroin consumption.

However, this does not mean that the scientific initiative of the Swiss heroin project is of small value. On the contrary, the Swiss heroin project is a positive example of how it is possible to use scientific research in order to influence the existing political and public positions and to increase treatment options. Accordingly, the response and interest in Europe is higher than it has been for other research projects. However, addiction research has many aspects, and many developments were only marginally noticed by the mass media. This is illustrated by the French review by the Institut National pour la Santé et la Recherche Médicale concerning the toxicity and an overall comparison of drugs. This study, commissioned by the French government and carried out by pharmacologists and other scientists, found that alcohol and nicotine, the most widespread drugs, cause the most somatic and mental harm and, therefore, are of greatest importance for addiction research, the help system and somatic medicine.

The discussion of this issue in the French-speaking European countries - often criticized for being too tolerant concerning alcohol consumption - might indicate a more evidence-based approach to addiction and a more rational evaluation of the risks of the different drugs. The contribution by Bloomfield et al. concerning the West German drinking patterns deals with the importance of alcohol and the development of an extensive and well-established epidemiological research in this area. The importance of this focus of research in Germany is also stressed by the overview of the 'analytical epidemiology of substance abuse' (ANEPSA). Particularly in this area, American research and epidemiology set examples; the epidemiological catchment area study or the national comorbidity study were milestones in psychiatric epidemiology. Perhaps, the ongoing European studies are steps towards an emancipation of addiction research from big brother America! The ANEPSA concept illustrates the fertile cooperation between clinicians and social researchers, between clinical relevance and methodology. This aspect of interdisciplinarity has always been a main concern of European Addiction Research.

The paper by Lenke and Olsson reflects a very special aspect of addiction research; they evaluate the Swedish experiment done between 1965 and 1967. Thus, comparing experiences made in different cultural and political settings is of major importance for a better, more patient-oriented drug policy.

Many differences in the regional help systems or preferences for certain maintenance medications cannot be explained by their pharmacological effects alone, for which buprenorphine, which is particularly widespread in French-speaking countries, is a most interesting example. The supplement of European Addiction Research on buprenorphine shows that experience with this maintenance medication is more interesting and differentiated than shown so far in Germanspeaking countries. These various experiences need to be taken into account for the development of a differentiated and patient-oriented pharmacological addiction research.

Thus, it was necessary to stress once again the whole scope of interdisciplinary addiction research by a variety of contributions without adhering to a special topic. European Addiction Research was conceived as an interdisciplinary European journal, and we are happy to register an increasing interest also in the United States and Australia as shown by the article by Swift et al.

We hope that by furthering the development of a systematic discussion between different positions, European Addiction Research will continue to be a public and especially European platform for interdisciplinary discussion on addiction research and be attractive for many new readers.

\section{KARGER}

(c) 1998 S. Karger AG, Basel

Fax + 41613061234

E-Mail karger@karger.ch

www.karger.com
Accessible online at:

http://BioMedNet.com/karger 